\title{
Characterization of the lipA gene encoding the major lipase from Pseudomonas aeruginosa strain IGB83
}

Received: 30 January 2001 / Received revision: 19 April 2001 / Accepted: 27 April 2001 / Published online: 17 July 2001

(C) Springer-Verlag 2001

\begin{abstract}
The lipases produced by Pseudomonas have a wide range of potential biotechnological applications. Pseudomonas aeruginosa IGB83 was isolated as a highly lipolytic strain which produced a thermotolerant and alkaline lipase. In the present work, we have characterized the $P$. aeruginosa IGB83 gene (lipA) encoding this enzyme. We describe the construction of a lipA mutant and report on the effect of two carbon sources on lipase expression.
\end{abstract}

\section{Introduction}

Lipases (E.C.3.1.1.3) are esterases able to hydrolyze water-insoluble esters such as long-chain triglycerides. These enzymes also catalyze the formation of esters (esterification) and the exchange of ester bonds (transesterification), when present in non-aqueous media (Jaeger et al. 1999). Lipases have a wide range of potential uses in industry (Jaeger et al. 1999; Soberón-Chávez and Palmeros, 1994). Pseudomonas lipases display special biochemical characteristics not common among the lipases produce by other microorganism, e.g., their thermoresistance and activity at alkaline $\mathrm{pH}$. The lipase produced by seudomonas aeruginosa LP602 has been shown to be useful for wastewater treatment (Dharmasthiti and Kuhasuntisuk 1998).

The genes encoding the lipase (lipA) of several P. aeruginosa strains have been cloned and sequenced (Jaeger et al. 1994, 1999; Rosenau and Jaeger 2000; SoberónChávez and Palmeros 1994), and the regulation of their expression is beginning to be understood (Jaeger et al. 1999; Rosenau and Jaeger 2000). For example, it is clear

\footnotetext{
A. Martínez · G. Soberón-Chávez (®)

Departamento de Microbiología Molecular, Instituto de

Biotecnología, Universidad Nacional Autónoma de México,

Apdo Postal 510-3, Cuernavaca, Morelos, 62251México

e-mail: gloria@ibt.unam.mx

Tel.: +52-73-291634, Fax: +52-73-172388
}

that $P$. aeruginosa LipA expression is subject to posttranscriptional regulation (Rosenau and Jaeger 2000).

$P$. aeruginosa IGB83 strain was isolated from the Mexican tropical rain forest as a highly lipolytic bacterium (Palmeros et al. 1994). Its major lipase was purified and shown to be a thermoresistant and alkaline $58-\mathrm{kDa}$ enzyme (Palmeros et al. 1994). We report here the characterization of the gene encoding the IGB83 lipase (lipA), showing that it is highly homologous to previously reported $P$. aeruginosa lipA genes and we describe the construction of a lipA-deficient mutant. We also demonstrate that $P$. aeruginosa IGB83 lipase expression is dependent on the carbon source used.

\section{Materials and methods}

Microbiological conditions

Bacterial strains were cultured in FAM+olive oil $(1 \% \mathrm{v} / \mathrm{v})$ and FAM+succinate $(50 \mathrm{mM})$ media (Palmeros et al. 1994). Olive oil and other fats were emulsified with a domestic blender, shaking for $15 \mathrm{~min}$. Antibiotics (Sigma) were used to supplement selection media at the following concentrations (in $\mu \mathrm{g} / \mathrm{ml}$ ) for $E$. coli and $P$. aeruginosa, respectively: ampicillin 100 and not used; carbenicillin not used and 150; tetracycline 15 and 200; and kanamycin 30 and not used. $\beta$-Galactosidase activity was determined as reported by Miller (1972). One unit corresponds to $1 \mathrm{~nm}$ of $O$-nitrophenyl$\beta$-D-galactopyranoside hydrolyzed per minute per $\mathrm{mg}$ of protein. All measurements were done in triplicate.

$P$. aeruginosa strain IGB83 has been deposited in the American Type Culture Collection under accession number ATCC BAA-228.

Determination of lipolytic activity

Qualitative determination of lipolityc activity was accomplished with two different assays: (1) by halo formation on LB medium supplemented with $1 \%$ glycerol tributyrate (this assay not only determines lipases, but also other esterases), and (2) a more specific assay on FAM+olive oil medium supplemented with $0.001 \%$ rhodamine B (Kouker and Jaeger 1987), visualizing the hydrolysis of olive oil by the fluorescence of rhodamine B. For quantitative determination of lipolityc activity, $p$-nitrophenyl palmitate (p-NPP) was used as substrate as described (Wolfgang et al. 1986). The reaction was carried out at $55^{\circ} \mathrm{C}$ on $50 \mathrm{mM}$ Tris- $\mathrm{HCl}$ buffer. 
Discontinuous SDS-PAGE was carried out using $12.5 \%$ polyacrylamide slab-gels. The samples were dissolved in a buffer containing $250 \mathrm{mM} \beta$-mercaptoethanol and $1 \%$ SDS and were boiled for $10 \mathrm{~min}$

\section{PCR amplification}

PCR primers for the lipA gene were designed based on conserved DNA sequences among 12 reported Pseudomonas lipA genes, including a PstI recognition site (underlined) to facilitate cloning of the PCR product. The sequence of these oligonucleotides is La: 5'GGTCAACCTGCAGGGCCACAGCCACGGCG-3'; and Ra: 5'GAGGCTGCAGAC CTGGTTCACCTCGTCCAGGTGG-3'. A single master mix was prepared containing approximately $100 \mathrm{ng}$ genomic DNA, $25 \mathrm{pmol}$ of each primer, $0.25 \mathrm{mM}$ dNTPs, and $1 \times$ buffer containing $1.25 \mathrm{mM} \mathrm{MgCl} 2$, using Vent DNA-polymerase (Biolabs). Cycling reactions were carried out in an automated RoboCycler Gradient 40 (Stratagene). The reaction conditions used are: 1 cycle $\left(95^{\circ} \mathrm{C}\right.$ for $\left.2 \mathrm{~min}\right), 25$ cycles $\left(95^{\circ} \mathrm{C}, 45 \mathrm{~s} ; 55^{\circ} \mathrm{C}\right.$, $\left.45 \mathrm{~s} ; 72^{\circ} \mathrm{C}, 1.5 \mathrm{~min}\right)$ and finally 1 cycle $\left(72{ }^{\circ} \mathrm{C}, 5 \mathrm{~min}\right)$.

Construction of the lipA IGB83 mutant (IGB0)

Plasmid pUC19 (Yanisch-Perron et al. 1985) containing a 558-bp internal lipA sequence (pMA558) was transformed to strain IGB83. Carbenicillin-resistant transformants are the product of single recombination events between plasmid pMA558, which is unable to replicate in $P$. aeruginosa, and the chromosomal lipA gene and resulted in inactivation of this gene. The transformants were screened for lipase deficiency on FAM+olive oil plates containing rhodamine $\mathrm{B}$ as described above.

\section{DNA procedures}

DNA isolation, cloning and sequencing, Southern blotting and nick-translation procedures were carried out as described (Sambrook et al. 1989). Plasmid DNA was introduced into E. coli (Sambrook et al. 1989) and P. aeruginosa (Irani and Rowe 1997) by transformation. The sequencing reactions were done using Taq fs DNA polymerase and fluorescent dideoxy terminators in a cycle sequencing method; the resultant DNA fragments were separated by electrophoresis and analyzed using an automated Applied Biosystems 377 DNA sequencer.

Nucleotide sequence accession number

The nucleotide sequence of the IGB83 lipA gene and flanking regions has been deposited in the GenBank database under accession number AF237723.

\section{Results}

Identification and characterization of the $P$. aeruginosa IGB83 lipA gene

The genes encoding the most abundant lipases (lipA) of $P$. aeruginosa and of closely related Pseudomonas species share a high degree of sequence similarity (SoberónChávez and Palmeros 1994). All of the lipases encoded by these genes have a molecular mass of around $30 \mathrm{kDa}$. In contrast, the major $P$. aeruginosa IGB83 lipase has an apparent molecular mass of $58 \mathrm{kDa}$ (Palmeros et al.

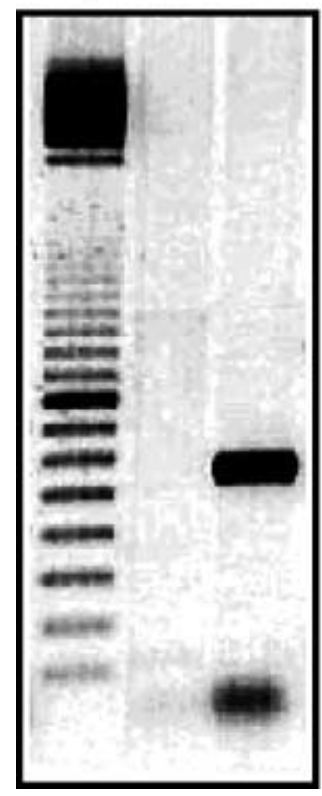

B)

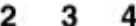

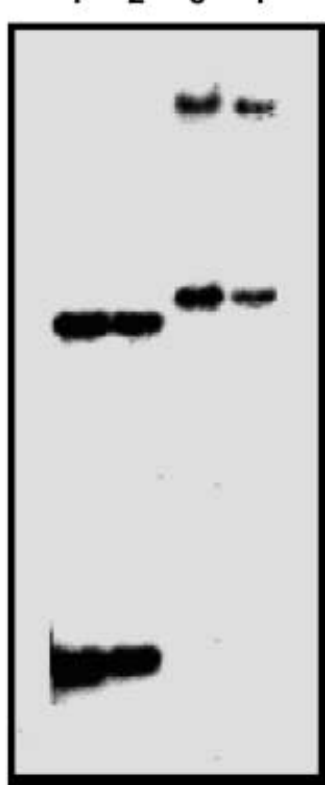

Fig. 1A, B Molecular characterization of the Pseudomonas aeruginosa strain IGB83 lipA gene. A PCR amplification of an internal lipA fragment. Lanes: 1 100-bp ladder molecular size markers, 2 PCR product using total strain IGB83 DNA as template. B Southern blot hybridization using an internal lipA fragment as probe. Lanes: 1 Total DNA of IGB83 strain digested with Pst 1 endonuclease, 2 total DNA of strain PAO1 digested with Pst 1 endonuclease, 3 total DNA of strain IGB83 digested with $E c o$ R1 endonuclease, 4 total DNA of strain PAO1 digested with EcoR1 endonuclease

1994). To determine whether strain IGB 83 contained a lipA homologue, a pair of oligonucleotides was designed (see Materials and methods) based on highly preserved regions of 12 bacterial lipA-homologous genes. These bacteria are P. aeruginosa, Pseudomonas fragi, Burkholderia glumae, Burkholderia cepacia and several Pseudomonas sp. strains. Using these oligonucleotides, a 558-bp band was amplified by PCR using strain IGB83 total DNA as template (Fig. 1A). The size of the amplified DNA sequence corresponded to that expected for the amplification of the $P$. aeruginosa lipA gene (Fig. 1A), and it was shown to correspond to an internal lipA fragment by DNA sequencing (data not shown). The IGB83 lipA PCR product was used as a probe in Southern blot hybridization with total DNA of $P$. aeruginosa strains PAO1 (Hancock and Carey 1979) and IGB83. The two strains presented an identical pattern of hybridization using different restriction enzymes (Fig. 1B).

To isolate the complete strain IGB83 lipA gene, a $P$. aeruginosa strain IGB83 genomic library (Wild et al. 1997) was screened by colony hybridization using the 558-bp lipA PCR product as probe. A cosmid clone (pMA721) was thus identified. A 6.5-kb BamH1 frag- 
A)

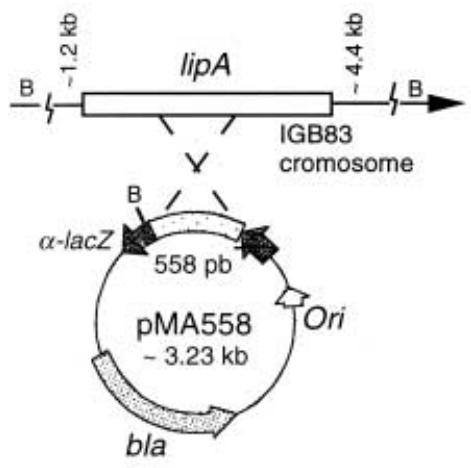

B)

$\begin{array}{llll}1 & 2 & 3 & 4\end{array}$

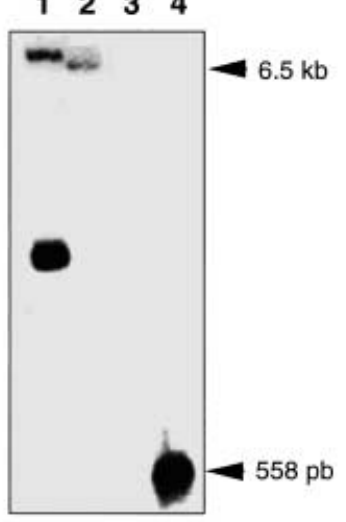

C)

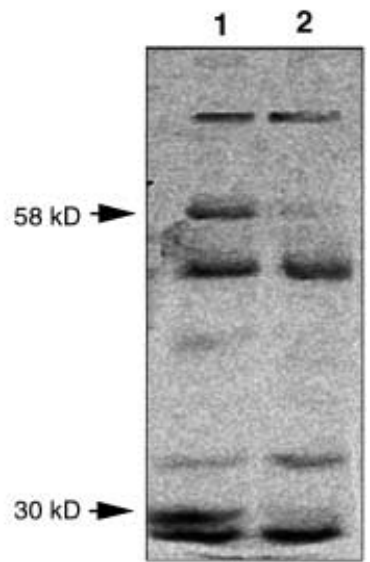

Fig. 2A-C Characterization of the $P$. aeruginosa strain IGB83 lipA mutant IGB0. A The molecular events leading to lipA disruption in strain IGB0. The size of the lines drawn is not a scale of the corresponding molecular sizes. B Southern blot hybridization using an internal 558-bp lipA fragment as probe of total DNA, digested with BamH1 endonuclease, of the IGB0 lipA mutant and wild-type strain IGB83. Lanes: 1 IGB0, 2 IGB83, 3 DNA molecular size markers, 4 PCR-amplified lipA fragment used as probe. $\mathbf{C}$ Extracellular protein profile of strain IGB83 (lane 1) and mutant IGB0 (lane 2). Arrows show the molecular mass in $\mathrm{kDa}$ of the proteins absent in the IGB0 supernatant

Table 1 Lipolytic activity of different Pseudomonas aeruginosa strains. The activity was determined in the culture supernatant from cells grown for $12 \mathrm{~h}$ in FAM+olive oil and using $p$-nitrophenylpalmitate as substrate. Lipase units correspond to nmol of hydrolyzed substrate per min and per mg of protein. lipA-, lipA chromosomal mutant; /lipA $A^{+}$, containing a plasmid carrying a functional $\operatorname{lip} A$ gene

\begin{tabular}{|c|c|c|}
\hline Strain (characteristics) & Lipase units & Percent \\
\hline IGB83 (wild-type) & $16.0 \pm 2.3$ & 100 \\
\hline IGB0 $\left(\operatorname{lip} A^{-}\right)$ & $3.9 \pm 1$ & 24 \\
\hline IGB0/pMA18 $\left(/ l i p A^{+}\right)$ & $14.8 \pm 3$ & 91 \\
\hline PAO1 (wild-type) & $13.2 \pm 1.6$ & 100 \\
\hline $29.1\left(\operatorname{lip}^{-}\right)$ & 0.12 & $<1$ \\
\hline 29.1/pMA18 $\left(/ l i p A^{+}\right)$ & $16.4 \pm 1.6$ & 123 \\
\hline
\end{tabular}

ment containing the lipA gene was subcloned into plasmid pUC19 (Yanisch-Perron et al. 1985), rendering plasmid pMA13, which was used as a template to sequence the entire lipA gene and 1,200 bp of its upstream region. The same 6.5-kb insert was cloned into plasmid pMP220, which is able to replicate in $P$. aeruginosa, rendering plasmid pMA18 (Table 1).

The IGB83 lipA gene codes for a prolipase of 311 amino acids with a signal peptide of 26 residues. The lipase has a molecular mass of $30.1 \mathrm{kDa}$, a $p \mathrm{I}$ of 5.8 , and is $99 \%$ identical to the lipase produced by $P$. aeruginosa strain PAO1 (http://www.pseudomonas.com), showing only two amino acid changes: isoleucine for valine at position 204, and glutamine for glutamic acid at position 280. Among the deduced protein sequence from the five
P. aeruginosa lipA genes sequenced to date (ChiharaSiomi et al. 1992; Ihara et al. 1991; Shinkai et al. 1996; Wohlfarth et al. 1992; GenBank accession number X63390 S43732), there are only seven amino acid changes, showing the high conservation of these enzymes.

\section{Construction of a $P$. aeruginosa IGB83 lipA mutant}

A strain IGB83 lipA mutant (IGB0) was isolated by selecting transformants with plasmid pMA558 inserted and disrupting the lipA gene (Fig. 2A). The disruption of the lipA gene in mutant IGB0 was determined by Southern blot hybridization (Fig. 2C). Mutant IGB0 had a 75\% reduction of lipase activity, measured with $p$-nitrophenyl palmitate as substrate when this strain was grown on FAM+olive oil (Table 1). The lipase deficiency of mutant IGB0 was complemented by plasmid pMA18 (Table 1). The PAO1-derived lipA mutant 29-1 (Wohlfarth et al. 1992) was also complemented by plasmid pMA18 (Table 1), confirming that it contained the strain IGB83 lipA gene. These results show that the strain IGB83 lipA gene encodes the major $P$. aeruginosa IGB83 lipase and suggest that the residual IGB0 lipase activity $(25 \%$, Table 1) is encoded by a different gene, as has been reported in other $P$. aeruginosa strains (Martínez et al. 1999).

The extracellular protein profile of strain IGB83 and its derived lipA mutant IGB0 showed that the latter strain produced very reduced amounts of the $30-\mathrm{kDa}$ and the 58-kDa band (Fig. 2B).

Effect of carbon source on the expression of $P$. aeruginosa IGB83 lipolytic activity and lipA expression

Strain IGB83 was isolated by its ability to grow on a mineral salt medium with olive oil as the only carbon source (FAM+olive oil), and was later shown to possess a high lipolytic activity (Palmeros et al. 1994). Strain IGB83 was able to grow on FAM+succinate with a doubling time of $1.1 \mathrm{~h}$, which is similar to the $1.25 \mathrm{~h}$ dou- 
Table 2 Lipase production and lipA expression ( $\beta$-galactosidase activity) of $P$. aeruginosa strain IGB83, with plasmids pMA19 and pMA77, grown on FAM medium with two different carbon sources. Lipase measurements were done using culture supernatants after 5 or $18 \mathrm{~h}$ of bacterial growth. Lipase units correspond to nmol of hydrolyzed substrate per minute and $\mathrm{mg}$ of protein. ND Not done

\begin{tabular}{|c|c|c|c|c|}
\hline \multirow[t]{2}{*}{ Carbon source } & \multicolumn{2}{|c|}{ Lipase units } & \multicolumn{2}{|c|}{$\beta$-galactosidase units } \\
\hline & Olive oil & Succinate & Olive oil & Succinate \\
\hline \multicolumn{5}{|l|}{ Strain } \\
\hline IGB83 (5 h) & $28.3 \pm 1.2$ & $50.3 \pm 2.0$ & ND & ND \\
\hline IGB83 (18 h) & $18.3 \pm 0.4$ & $56.6 \pm 0.5$ & ND & ND \\
\hline IGB83/pMA19 (5 h) & $28.2 \pm 1.0$ & $45.0 \pm 0.8$ & $352 \pm 22$ & $867 \pm 104$ \\
\hline IGB83/pMA19 (18 h) & $21.0 \pm 5.3$ & $53.0 \pm 0.8$ & $70 \pm 11$ & $49 \pm 4$ \\
\hline IGB83/pMA77 (5 h) & $30.5 \pm 3.9$ & $53.0 \pm 1.0$ & $70 \pm 4$ & $33 \pm 2$ \\
\hline IGB83/pMA77 (18 h) & $25.6 \pm 1.9$ & $52.3 \pm 0.4$ & $93 \pm 30$ & $36 \pm 3$ \\
\hline
\end{tabular}

bling obtained in FAM+olive oil medium. To study the effect of the carbon source on strain IGB83 lipase expression, these two media were used. The results show that strain IGB83 lipase is expressed at a lower level in FAM+olive oil medium than in FAM+succinate medium (Table 2).

To study transcriptional regulation of the strain IGB83 lipA gene, a lipA::lacZ fusion was constructed by cloning 1,200 bp, including 1,081 bp of the $5^{\prime} \operatorname{lip} A$ untranslated sequence, into plasmid pMP220 (Spaink et al. 1987 ) in the correct orientation (plasmid pMA19). The 1,200 bp lipA $5^{\prime}$ region was isolated by PCR (data not shown). As a control, the same DNA sequence was cloned into the same plasmid, but in the opposite orientation (plasmid pMA77).

The expression of the lipA::lacZ gene fusion of plasmid pMA19 was studied in logarithmic and stationary phase cultures of strain IGB83 in FAM+succinate and FAM+olive oil media (Table 2). Expression of the IGB83 lipA gene was significantly higher in FAM+succinate medium, corresponding to the higher lipase activity detected under this condition, and was completely abrogated in the stationary phase of growth in cells grown on either medium (Table 2).

\section{Discussion}

We have previously reported the purification of the $P$. aeruginosa strain IGB83 lipase, showing that it was a 58-kDa protein (Palmeros et al. 1994). In this work we have shown that the strain IGB83 lipA gene codes for a $30-\mathrm{kDa}$ protein, and that the lipA mutant IGB0 has greatly reduced levels of both the $58-\mathrm{kDa}$ and the $30-\mathrm{kDa}$ extracellular proteins. These results, together with the significant reduction of IGB0 lipase activity, strongly suggest that the strain IGB83 lipase is the dimer of the enzyme encoded by the lipA gene and that it was not completely denatured to the $30-\mathrm{kDa}$ monomers under the SDS-PAGE conditions used. In contrast with our results, the apparent molecular mass of the $P$. aeruginosa LipA of different isolates is $30 \mathrm{kDa}$ (Jaeger et al. 1994, 1999; Rosenau and Jaeger 2000; Soberón-Chávez and Palmeros 1994). The difference in the apparent molecular mass of the IGB83 LipA protein and other P. aeruginosa lipases might be due to differences in protein associa- tion, which most likely are due to posttranslational modification of the lipase in the IGB83 background, since the primary structure of all the reported $P$. aeruginosa LipA enzymes is almost identical. This hypothesis remains to be experimentally validated.

We isolated strain IGB83 on the basis of its ability to use olive oil as sole carbon source (Palmeros et al. 1994). Here we studied the level of lipase production and lipA expression using both olive oil and succinate as carbon sources and found that the lipolytic activity is higher on FAM+succinate medium. Furthermore, under this condition the $\operatorname{lip} A$ gene is expressed at a significantly higher rate (Table 2). This pattern of lipase expression, while not incompatible with a role for the LipA enzyme in olive oil assimilation, shows that the expression of lipase activity is not related to substrate availability and suggests that LipA activity is not responsible for the growth of strain IGB83 on olive oil as carbon source. In agreement with the lack of relationship between lipase expression and olive oil assimilation, the strain IGB0 lipA mutant showed a growth rate on FAM+olive oil medium that was similar to that of its parental strain IGB83 (data not shown).

Acknowledgements This work was financed in part by CONACyT through projects 0111P-N9506, 31698-N and 0028. The authors thank Eugenio López and René Hernández for technical assistance. Agustino Martínez held a CONACyT scholarship during the development of this project.

\section{References}

Chihara-Siomi M, Yoshikawa K, Oshima-Hirayama N, Yamamoto K, Sogabe Y, Nakatani T, Nishioka T, Oda J (1992) Purification, molecular cloning, and expression of lipase from Pseudomonas aeruginosa. Arch Biochem Biophys 296:505-513

Dharmsthiti S, Kuhasuntisuk B (1998) Lipase from Pseudomonas aeruginosa LP602: biochemical properties and application for wastewater treatment. J Indian Microbiol Biotechnol 21:75-80

Hancock REW, Carey AM (1979) Outer membrane of Pseudomonas aeruginosa: heat-and 2-mercaptoethanol-modifiable proteins. J Bacteriol 140:902-910

Ihara F, Kageyama Y, Hirata M, Nihira T, Yamada Y (1991) Purification, characterization and cloning of a lactonizing lipase from Pseudomonas species. J Biol Chem 266:18135-18140

Irani V, Rowe J (1997) Enhancement of transformation in Pseudomonas aeruginosa $\mathrm{PAO} 1$ by $\mathrm{Mg} 2+$ and heat. Biotechniques 22:54-56

Jaeger K-E, Ransac S, Dijkstra BW, Colson C, Heuvel M, Misset O (1994) Bacterial lipases. FEMS Microbiol Rev 15:29-63 
Jaeger K-E, Dijstra B W, Reetz MT (1999) Bacterial byocatalyst: Molecular biology, three-dimensional structures, and biotechnological applications of lipases. Annu Rev Microbiol $56: 315-351$

Kouker G, Jaeger K-E (1987) Specific and sensitive plate assay for bacterial lipases. Appl Environ Microbiol 53:211-213

Martínez A, Ostrovsky P, Nunn D (1999) LipC, a second lipase of Pseudomonas aeruginosa, is LipB and Xcp dependent and is transcriptionally regulated by pilus biogenesis components. Mol Microbiol 34:317-326

Miller JH (1972) Experiments in molecular genetics. Cold Spring Harbor Laboratory, Cold Spring Harbor, New York, pp 431-435

Palmeros B, Guereca L, Alagon A, Soberón-Chávez G (1994) Biochemical characterization of the lipolytic activity of Pseudomonas aeruginosa IGB 83. Process Biochem 29: 207-212

Rosenau F, Jaeger K-E (2000) Bacterial lipases from Pseudomonas: Regulation of gene expression and mechanism of secretion. Biochimie 82:1023-1032

Sambrook J, Maniatis T,Fritsch E (1989) Molecular cloning: a laboratory manual. Cold Spring Harbor Laboratory, Cold Spring Harbor, New York
Shinkai A, Hirano A, Aisaka K (1996) Substitutions of Ser for Asn-163 and Pro for Leu-264 are important for thermal stabilization of lipase from Pseudomonas aeruginosa. J Biochem 120:915-921

Soberón-Chávez G, Palmeros B (1994) Pseudomonas lipases: Molecular genetics and potential industrial applications. Crit Rev Microbiol 20:95-105

Spaink H, Okker R, Wijffelman C, Pees E,Lugtenberg B (1987) Promoters in the nodulation region of the Rhizobium leguminosarum Sym plasmid pRL1Jl. Plant Mol Biol 9:27-39

Wild M, Caro AD, Miller RM, Soberón-Chávez G (1997) Selection and partial characterization of a Pseudomonas aeruginosa mono-rhamnolipid deficient mutant. FEMS Microbiol Lett 153:279-285

Wohlfarth S, Hoesche C, Strunk C, Winkler UK (1992) Molecular genetics of the extracellular lipase of Pseudomonas aeruginosa PAO1. J Gen Microbiol 138:1325-1335

Wolfgang S, Jaeger KE, Winkler UK (1986) Purification of extracellular lipase from Peudomonas aeruginosa. J Bacteriol 168:1070-1074

Yanisch-Perron C, Vieira J, Messing J (1985) Improved M13 phage cloning vectors and host strains: nucleotide sequences of the M13mp18 and pUC19 vectors Gene 33:103-119 